\title{
DESAFIOS EDUCACIONAIS DO TEMPO PRESENTE
}

O vigésimo sétimo número da Revista Sul-Americana de Filosofia e Educação (RESAFE), aparece em meio a um dos momentos mais críticos da história recente. O Ocidente parece estar imerso em uma intensa crise de representatividade políticoinstitucional, profundas dúvidas sobre os modelos de gestão dos interesses comuns, um temerário fortalecimento de discursos reacionários em política... Esses elementos impactam de modo decisivo a Educação e nossos modos de pensar o futuro.

Especificamente no caso do Brasil, a crise política e econômica tem instalado um cenário sombrio em torno das instituições educativas, com mudanças legislativas não discutidas com a sociedade civil, na esfera da Educação Básica, falta de recursos bastante dramática nas instituições de formação superior.

Nesse contexto, uma série de desafios educacionais se mostram urgentes ao nosso redor. Mais que nunca a necessidade de refletir criticamente sobre o mundo que nos cerca é imperiosa e é fundamental que nossas reflexões sejam partilhadas, disseminadas, discutidas, na busca de criarmos estratégias para lidar com esse profundo abalo que nos atinge no tempo presente. Em meio a esse turbilhão da atualidade, a RESAFE traz algumas reflexões que foram partilhadas por nossas/os colaboradoras/es, que lidam com dimensões distintas das interfaces entre a filosofia e a educação.

O texto de Angélica Neuscharank, Alice Copetti Dalmaso, Ana Claudia Barin e Marilda Oliveira de Oliveira problematiza relações de afeto experimentadas a partir da literatura de Marcel Proust, Mia Couto e Neil Gaiman, partindo dos conceitos de encontros com signos, devir e fabulação, buscando outros olhares em direção à docência.

Uma instigante leitura da educação do campo na universidade é realizada por Bruno Gonçalves Borges, por meio de categorias deleuzianas como acontecimento, agenciamento e desejo, lidando com a potência das pessoas que vivem no campo $e$ apresentando uma interessante crítica à implementação das políticas sobre educação do campo.

A problematização da avaliação de aprendizagem em filosofia foi tematizada no artigo de Carlos Augusto Pereira de Sousa que, ao lidar com as Orientações Curriculares Nacionais e com o Currículo de Filosofia do Estado de São Paulo, toma como abordagem o tratamento do ensino de filosofia por meio de competências $e$ habilidades para refletir sobre processos avaliativos.

$\mathrm{O}$ artigo de Christian Fernando Ribeiro Guimarães Vinci revisita as pesquisas educacionais brasileiras em busca do modo como o referencial pós-estruturalista se articulou com o contexto da educação, observando um deslocamento da tarefa crítica em direção da inserção da afecção nas pesquisas em pauta.

As relações entre a filosofia e a vida são o tema do texto de Denis Domeneghetti Badia e Paula Ramos de Oliveira, que buscam, por meio da obra de Michel Onfray e seu "projeto existencial", entender de que modos a criação de um novo imaginá- 
rio e um novo logos filosófico podem colaborar para um reencantamento artístico da cultura escolar, tendo a estética como um modo político de habitar o pensamento.

Partindo da filosofia da educação, Fernanda Antônia Barbosa da Mota e Heraldo Aparecido Silva examinam a noção de experiência frente às transformações dos ideais formativos e tecendo uma crítica à redução da experiência ao empírico e, desde a formação, indicam rotas para a retomada da noção da experiência revitalizada nas pesquisas educacionais.

Tendo a temática foucaultiana da governamentalidade, o artigo de José Luís Schifino Ferraro discute o movimento das ocupações de escolas públicas brasileiras no final de 2015 e início de 2016, observando as estratégias de resistência e contraconduta nas intervenções desse movimento, entendendo a dimensão política do protagonismo estudantil.

Kelvin Custódio Maciel articula um diálogo entre o pensamento de Platão e Comênio, em torno da possibilidade de aprender e ensinar, partindo do suposto que para ambos os autores a educação é o processo fundamental para o desenvolvimento do ser humano $e$ abordando a tarefa formativa para além da técnica e da transmissão de informações.

A teoria dos afetos em Spinoza é evocada pelo texto de Marcela Fernandes Silva para pensar a potencialização dos corpos no ambiente escolar, acontecimento que surge, para a autora como estratégia importante para a compreensão da importância dos afetos no processo de humanização.

A temática das habilidades e competências no ensino de filosofia é novamente abordada pela pesquisa de Marcos Alexandre Alves, que busca, desde a percepção de professores de filosofia do Ensino Médio e uma discussão sobre teoria e legislação, entender sobre os alcances e limites do trabalho em sala de aula para o desenvolvimento das habilidades e competências em filosofia.

O trabalho de Neyha Guedes Dariva e Elisete Medianeira Tomazetti problematiza um dos mais centrais conceitos modernos trazidos à educação: a emancipação, tal como o Iluminismo a pensou. Em que medida, em nossa contemporaneidade esse conceito se efetiva e como repensar essa questão, desde uma perspectiva crítica, nos auxilia a reflexão sobre a atividade docente e o papel da educação? Essas são questões que atravessam o texto.

A partir de uma pesquisa que mapeou as instituições de ensino superior que formam docentes para a filosofia $e$ numa interlocução com professores do ensino médio de Uberaba, o trabalho de Osvaldo Dalberio investiga a formação inicial desses docente e sua efetiva preparação para o magistério em filosofia.

O sensivel trabalho de Víviam Carvalho de Araújo aborda as relações entre a filosofia, infância e educação, buscando compreender e promover um deslocamento de uma imagem da infância a ser meramente educada para outras possibilidades da infância como intensidade, presença $e$ experiência, como fenômenos que educam.

Yvisson Gomes dos Santos nos apresenta uma revisão histórica da presença da filosofia na educação média brasileira desde a presença dos jesuítas até a última LDB, promulgada em 1996, acompanhan- 
do as modificações das políticas educacionais brasileiras e suas relações com o ensino de filosofia.

A partir do trabalho com o PIBID em uma escola do interior de Santa Catarina, Luiz Carlos de Abreu nos apresenta um relato de experiência sobre o trabalho com a história da filosofia no Ensino Médio, com a leitura de textos clássicos para abordar os temas de Eros e Philia no pensamento de Platão e Aristóteles.

Estas diversas abordagens dos encontros entre a filosofia e a educação são parte pequena, mas importante do conjunto de reflexões que se fazem necessárias para que possamos encontrar alternativas para os desafios colocados presentemente para a educação. $\mathrm{O}$ pensamento tem sido demandado em sua dimensão mais crítica e criativa. Aqui é necessário que nos coloquemos na tarefa dupla de apostar na educação pelo pensamento e apostar no pensamento pela educação.

Boa leitura!

wanderson flor do nascimento

co-editor 